\title{
High Resolution Flash Flood Forecasting for the Dallas-Fort Worth Metroplex
}

\author{
Hamideh Habibi, ${ }^{1}$ Arezoo Rafieei Nasab, ${ }^{1}$ Amir Norouzi, ${ }^{1}$ Behzad Nazari, ${ }^{1}$ Dong-Jun Seo, ${ }^{1}$ Ranjan \\ Muttiah $^{2}$ and Clair Davis ${ }^{2}$ \\ ${ }^{1}$ University of Texas at Arlington, Arlington, Texas; ${ }^{2}$ City of Fort Worth, Fort Worth, Texas.
}

\begin{abstract}
Urban flash flooding is a serious problem in large highly populated areas such as the Dallas-Fort Worth metroplex (DFW). Being able to monitor and predict flash flooding at a high spatiotemporal resolution is critical to mitigating its threats and for cost effective emergency management. In this work, the prototype high resolution flash flood warning system under development for DFW is described and a case study of the flash flooding event of 2014-06-24 in Fort Worth presented. The high resolution (500 m, $1 \mathrm{~min}$ ) precipitation input comes from the DFW Demonstration Network of the Collaborative Adaptive Sensing of the Atmosphere (CASA) X-band radars. The hydrologic model used is the National Weather Service Hydrology Laboratory's Distributed Hydrologic Model (HL-RDHM) operating at a $500 \mathrm{~m}$ resolution. The model simulation results are assessed using the flooding reports received from residents throughout the event by the City of Fort Worth.
\end{abstract}

\section{Introduction}

More than three-quarters of the population of the United States lives in urban areas that comprise only about $3 \%$ of the total land area. According to the U.S. Census Bureau, the urban population increased by $12.1 \%$ from 2000 to 2010 compared to the overall population increase of $9.7 \%$ for the same period. For the 486 large urbanized areas, the rate was even higher at $14.3 \%$. Given the high population density, high resolution observations and modeling capabilities are necessary for the prediction of flash floods in urban areas. The increasing occurrences of extreme precipitation expected from the changing climate have put such areas in an increasingly vulnerable position as even a small but intense rainfall event can cause deadly flash floods and extensive damages. If effective high resolution prediction and warning capabilities were to exist for all urban areas, many lives would be saved and economic losses would be greatly reduced.

For high resolution observations and modeling of large urban areas, the use of weather radar and distributed hydrologic modeling is a natural progression. In this paper, the prototype high resolution flash flood warning system under development for DFW is described and a case study of the flash flooding event of 2014-06-24 in Fort Worth presented. Two radar based quantitative precipitation estimators (QPE) were used in this study: the higher resolution (500 $\mathrm{m}, 1 \mathrm{~min}$ ) QPE from the X-band radar at the University of Texas at Arlington, which is part of the DFW Demonstration Network of CASA radars (see Figure 2 below), and the lower resolution ( $4 \mathrm{~km}, 1 \mathrm{~h}$ ) multisensor QPE from the multisensor precipitation estimator (MPE) operated by the
National Weather Service (NWS) West Gulf River Forecast Center (WGRFC). The model simulation results are qualitatively assessed based on the location and timing of local flooding as reported by the residents of Fort Worth throughout the event.

\section{Study Area and Precipitation Data Used}

The study area is DFW in North Texas, which is the fourth largest metropolitan area in the United States by population. The area of interest in this study is comprised of Fort Worth, Arlington and Grand Prairie (see Figure 1). Also shown in the figure is Dallas, which will also be modeled in the very near future.

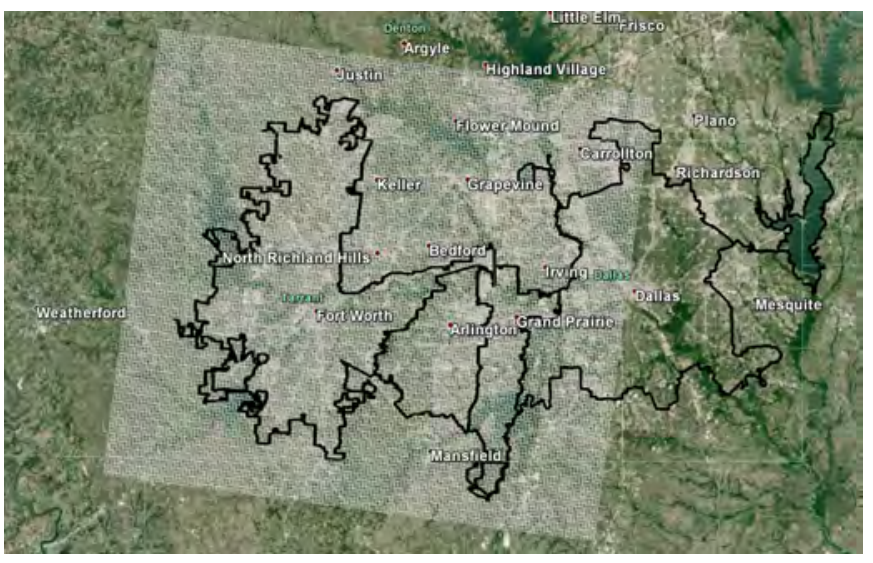

Figure 1 The HL-RDHM domain encompassing Fort Worth, Arlington and Grand Prairie; overlaid is the $500 \mathrm{~m}^{2} \times 500 \mathrm{~m}^{2}$ CASA QPE grid.

Habibi, H., A. Rafieei Nasab, A. Norouzi, B. Nazari, D. Seo, R. Muttiah and C. Davis. 2016. "High Resolution Flash Flood Forecasting for the Dallas-Fort Worth Metroplex." Journal of Water Management Modeling C401. doi: 10.14796/JWMM.C401.

(c) CHI 2016 www.chijournal.org ISSN: 2292-6062 
For precipitation forcing, the QPEs from the MPE (Seo et al. 2010; Kitzmiller et al. 2011) and from the DFW Demonstration Network of CASA radars are used. The MPE product, which is routinely used in operational hydrologic forecasting, is obtained from WGRFC and has a spatiotemporal resolution of 1 hydrologic rainfall analysis projection ( $1 \mathrm{HRAP}$, approximately $4 \mathrm{~km} \times 4 \mathrm{~km}$ ) and $1 \mathrm{~h}$.

One of the limitations of NEXRAD (Next Generation Radar) data is that they do not observe the lower atmosphere away from the radar, which causes degradation of spatial resolution at far ranges. Also, the temporal resolution is constrained by a fixed set of volume coverage patterns. This lack of resolution arises because the radar operation is independent of the weather conditions. To maximize its utility, the radar may adapt to the time-varying needs of the users (Junyent et al. 2010). To address these gaps in the current weather observation system, the NSF Engineering Research Center (ERC) for CASA developed a new weather warning system based on dense networks of small radars (McLaughlin et al. 2005) with an adaptive scanning strategy (Junyent et al. 2010). The CASA Integrated Project was the first testbed of a networked CASA radar system composed of four X-band radars in Oklahoma. Each radar node was approximately $30 \mathrm{~km}$ distant from the next unit. The details of the radar network hardware and software architectures are described in Junyent et al. 2010. The network was evaluated using rain gauge observations for a 5 y period which showed a good agreement between radar QPE and rain gauge observations with a standard deviation of 25\% and a bias of 3.7\% (Chandrasekar and Cifelli 2012).

Because CASA QPE is based on a specific differential propagation phase, it is immune to absolute calibration errors (Bringi and Chandrasekar 2001). Attenuation is a known issue for precipitation estimation using X-band radars (Seo et al. 2010; Berne and Krajewski 2013). The CASA system uses the network reflectivity retrieval technique (Chandrasekar and Lim 2008) and the network based attenuation correction technique (Lim et al. 2011) to mitigate the effects of attenuation. Lim et al. (2011) showed that the technique works robustly in real time in retrieving attenuation corrected reflectivity.

A network of four CASA X-band radars, the DFW Demonstration Network, has been deployed in the area thus far. Figure 2 shows the radar locations at the University of Texas at Arlington (UTA), Cleburne, Midlothian and Addison, and their coverage. The network is expected to expand to seven or eight locations in 2015. Radar QPE from the network is based on:

$$
R=18.15 K D P^{0.791}
$$

where:

$$
\begin{aligned}
R & =\text { rain rate }(\mathrm{mm} / \mathrm{h}), \text { and } \\
K D P & =\text { specific differential phase }(\% / \mathrm{km}) .
\end{aligned}
$$

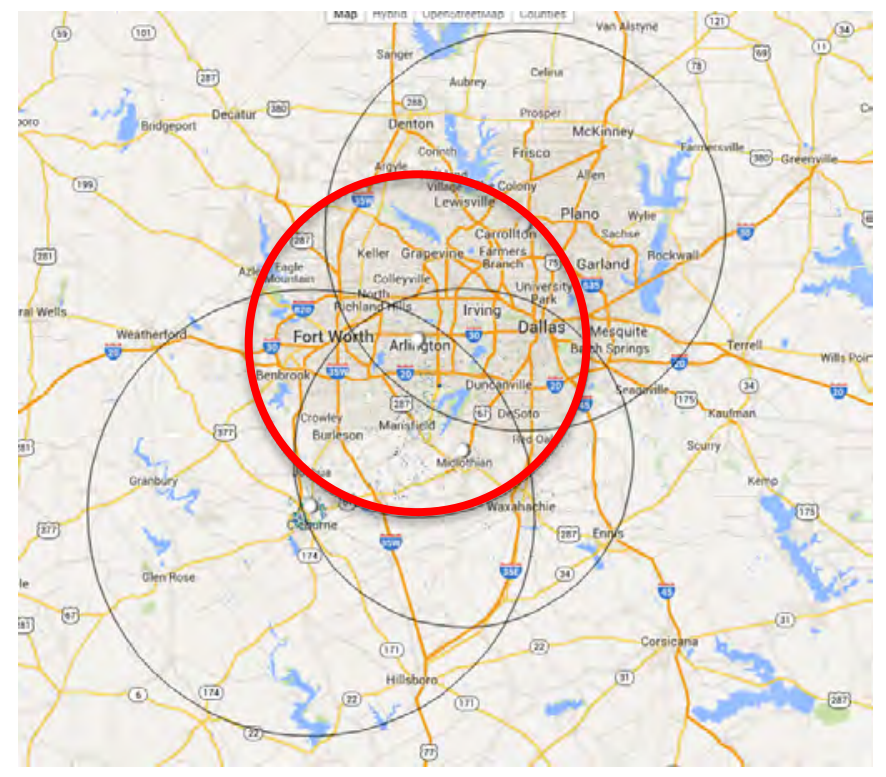

Figure 2 The DFW demonstration network (the red circle indicates the UTA radar coverage).

The spatiotemporal resolution of the QPE from the DFW Demonstration Network is $500 \mathrm{~m}$ and $1 \mathrm{~min}$. The QPE products include instantaneous rain rate and $1 \mathrm{~h}$ and $3 \mathrm{~h}$ rainfall accumulations. Recently, comparative evaluation of different radar based QPE products was carried out based on a limited period of record of about 1 y (Rafieei Nasab et al. 2014; Rafieei Nasab et al. 2015). The results show that, in general, the CASA QPE is more accurate for larger precipitation amounts whereas the MPE estimates are more accurate for smaller amounts in the study area.

\section{Hydrologic Model}

The distributed hydrologic model used in this work is the Hydrology Laboratory-Research Distributed Hydrologic Model (HL-RDHM) developed by the NWS Hydrology Laboratory (HLRDHM 2009; Koren et al. 2004). Koren et al. (2004) showed that HL-RDHM results are comparable to well calibrated lumped model simulations, and that the former outperform the latter when spatial rainfall variability is significant. The operational version of HL-RDHM, the Distributed Hydrologic Model (DHM), is used at various river forecast centres (RFC) for flash flood and river flood forecasting.

For rainfall-runoff modeling, the Sacramento soil moisture accounting (SAC-SMA) model is used. For routing of hillslope and channel flows, kinematic wave routing is used. SAC-SMA was first introduced by Burnash et al. (1973; see Figure 3) and has been used widely from local to continental scales. SAC-SMA is a conceptual model of the land surface phase of the hydrologic cycle. It accounts for percolation, soil moisture storage, drainage and evaporation processes. The model inputs rainfall, evaporation and snow cover (optional) and outputs runoff to the channel system. The basic SAC-SMA has sixteen parameters, of which the most important are given in Table 1. 


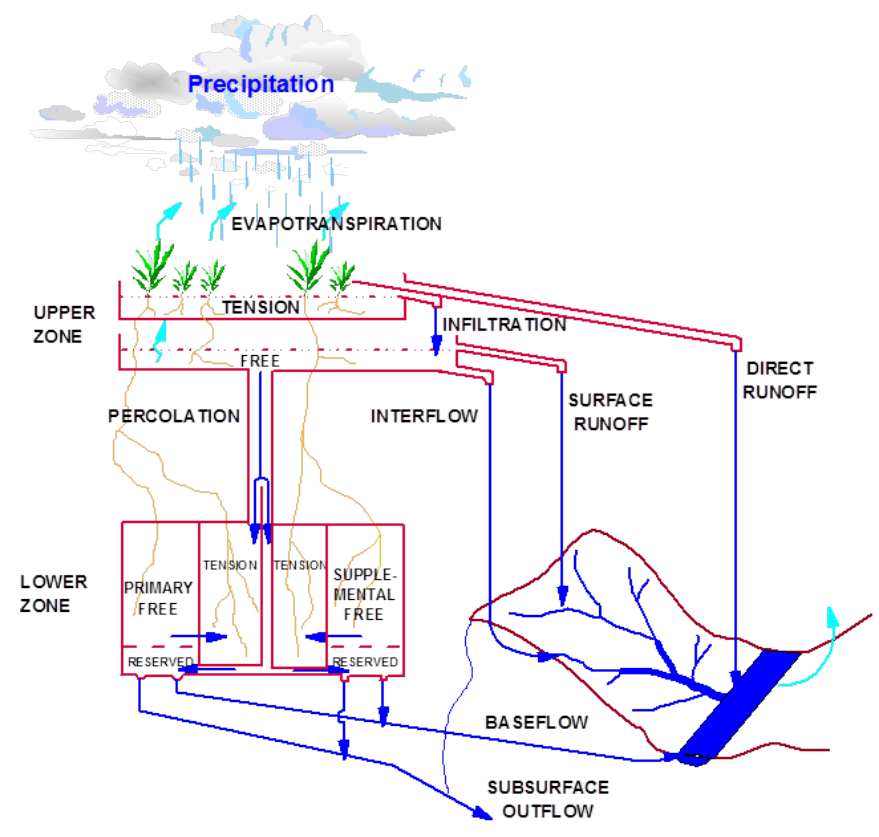

Figure 3 Schematic of the SAC-SMA model.

Table 1 SAC-SMA parameters, the units and description.

\begin{tabular}{ccl}
\hline Parameters & Units & \multicolumn{1}{c}{ Description } \\
\hline UZTWM & $\mathrm{mm}$ & Upper zone tension water maximum storage \\
UZFWM & $\mathrm{mm}$ & Upper zone free water maximum storage \\
LZTWM & $\mathrm{mm}$ & Lower zone tension water maximum storage \\
LZFSM & $\mathrm{mm}$ & Lower zone free water supplementary maximum storage \\
LZFPM & $\mathrm{mm}$ & Lower zone free water primary maximum storage \\
UZK & day $^{-1}$ & Upper zone free water withdrawal rate \\
LZSK & day $^{-1}$ & Lower zone supplementary withdrawal rate \\
LZPK & day $^{-1}$ & Lower zone primary withdrawal rate \\
PCTIM & $\%$ & $\%$ permanent impervious area \\
ADIMP & $\%$ & $\%$ area contributing as impervious when saturated \\
RIVA & $\%$ & $\%$ area affected by riparian vegetarian, streams and lakes \\
ZPERC & none & Maximum percolation rate under dry condition \\
REXP & none & Percolation equation exponent \\
PFREE & $\%$ & $\%$ of percent going directly to lower zone free water \\
\hline
\end{tabular}

Koren et al. (2000) and Koren et al. (2003) related the SACSMA parameters with soil properties such as porosity, field capacity and wilting point, and derived a priori settings for a subset of the SAC-SMA parameters using the U.S. Department of Agriculture's State Soil Geographic Database (STATSGO) soil texture data in eleven soil layers.

Anderson et al. (2006) and Zhang et al. (2006) improved the quality of the a priori parameters by replacing the STATSGO data with the finer scale Soil Survey Geographic Database (SSURGO). The a priori grids of the SAC-SMA and kinematic wave routing parameters are provided by NWS for the continental United States at a $4 \mathrm{~km} \times 4 \mathrm{~km}$ resolution. For modeling at higher resolutions, it is necessary to re-derive the parameters using higher resolution physiographic data.

Because impervious areas play a very important role in rainfall-runoff processes in urban areas, it is important that they are delineated with high accuracy and resolution. In this study, the percent impervious area maps (PCTIM in Table 1) based on a set of GIS layers obtained from the Cities of Fort Worth, Arlington and Grand Prairie are derived (see Table 2). Figure 4 shows the resulting PCTIM map at a $500 \mathrm{~m}$ resolution over the three cities.

Table 2 GIS layers from Fort Worth, Arlington and Grand Prairie used for estimation of PCTIM.

\begin{tabular}{lccc}
\hline \multicolumn{1}{c}{ Map Layer } & Fort Worth & Arlington & Grand Prairie \\
\hline Building footprint & $\sqrt{ }$ & $\sqrt{ }$ & $\sqrt{ }$ \\
Impervious cover of commercial & $\sqrt{ }$ & - & $\sqrt{ }$ \\
Pavements & $\sqrt{ }$ & $\sqrt{ }$ & - \\
Centerline of sidewalk & $\sqrt{ }$ & - & - \\
Centerline of streets & - & - & $\sqrt{ }$ \\
\hline
\end{tabular}

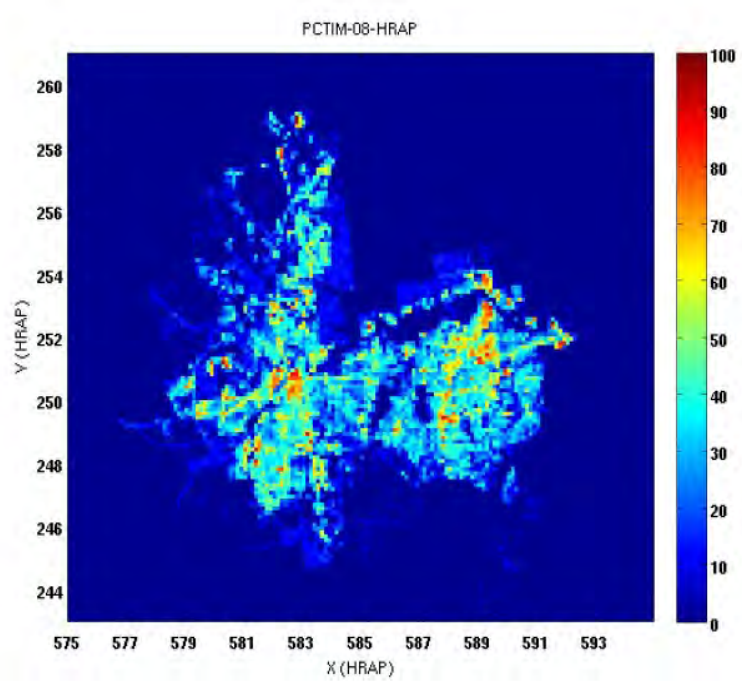

Figure 4 PCTIM at $500 \mathrm{~m}$ resolution within Fort Worth, Arlington and Grand Prairie.

Hillslope and channel routing in HL-RDHM is performed using kinematic wave routing (Chow et al. 1988; Koren et al. 2004). HL-RDHM routes runoff through the natural channels identifiable from the digital elevation model (DEM) by the Cell Outlet Tracing with an Area Threshold (COTAT) algorithm (Reed et al. 2002). Within each cell, fast runoff is first routed over conceptual hillslopes, and then the combination of channel inflow from hillslope routing, slow (i.e. subsurface or ground) runoff and inflow from upstream cells is routed via channel routing (Koren et al. 2004). A conceptual hillslope consists of multiple uniform hillslopes, the number of which depends on the stream channel density specified for the cell. The conceptual channel that transfers water from one cell to another usually represents the highest order stream in the cell selected. The cell-to-cell connectivity is used to transfer water from upstream to downstream cells and to the basin outlets. For hillslope routing, discharge per unit area of hillslope $\left(q_{h}\right)$ is given (Koren et al. 2004) by:

$$
q_{h}=2 k_{q} D \frac{\sqrt{s_{h}}}{n_{h}} h^{5 / 3}
$$


where:

$k_{q}=$ unit transformation coefficient,

$D=$ stream channel density in $\mathrm{km}^{-1}$,

$S_{h}=$ hillslope slope,

$n_{h}=$ hillslope roughness coefficient, and

$h=$ average depth of water on the hillslope.

For channel routing, the discharge for each cell, $Q_{c^{\prime}}$ is defined as:

$$
Q_{c}=q_{0} A^{q_{m}}
$$

where:

$$
A=\text { cross sectional area, }
$$

$q_{0}=$ specific discharge (i.e. discharge per unit channel cross section area), and

$q_{m}=$ exponent in the power-law relationship.

The specific discharge may be evaluated if $A$ and $Q_{c}$ are known. Mean annual flow may be derived from the mean average annual runoff data over the continental United States available from the United States Geological Survey (USGS) (Slack and Landwehr 1992). The wetted channel cross section, $A$, may be obtained from:

$$
A=Q / V
$$

where:

$$
V=\text { the mean velocity. }
$$

The mean velocity may be evaluated using the empirical equation developed by Jobson (1996):

$$
V=0.094+0.0143\left(\frac{D_{a}^{1.25} \sqrt{g}}{Q}\right)^{0.919} S^{0.159} \frac{Q}{D_{a}}
$$

where:

$$
\begin{aligned}
& D_{a}=\text { upstream drainage area calculated using the flow } \\
& \quad \text { direction and cell size grids, } \\
& g=\text { gravitational acceleration, and } \\
& S=\text { channel slope. } \\
& \text { The two kinematic wave channel routing parameters, }
\end{aligned}
$$
$q_{0}$ and $q_{m}$, were derived using the above relationships and the National Elevation Dataset (NED) with $30 \mathrm{~m}$ resolution from the NHDPlus version 2 dataset (David et al. 2011). Figure 5 opposite shows the derived specific discharge at different resolutions over the model domain.

\section{Case Study}

To assess the performance of the system, the flash flooding event of 2014-06-24 in Fort Worth is used which 2 in. $(5.1 \mathrm{~mm})$ to $3 \mathrm{in}$. $(7.6 \mathrm{~mm})$ rain fell in just $90 \mathrm{~min}$. The largest rainfall in June since 2007 , the rain event was the result of small impulses moving through the upper level in which disturbances rotated around the low. The heaviest rain occurred where the boundaries intersected (Dallas News 2014). Over $3 \mathrm{~h}$ in the afternoon of 2014-06-24, Fort Worth fire officials responded to 420 calls. More than 40 of the calls were high water rescues, $>20$ were for downed power lines, and 8 fire calls were made during the flooding (Fox4 News 2014).
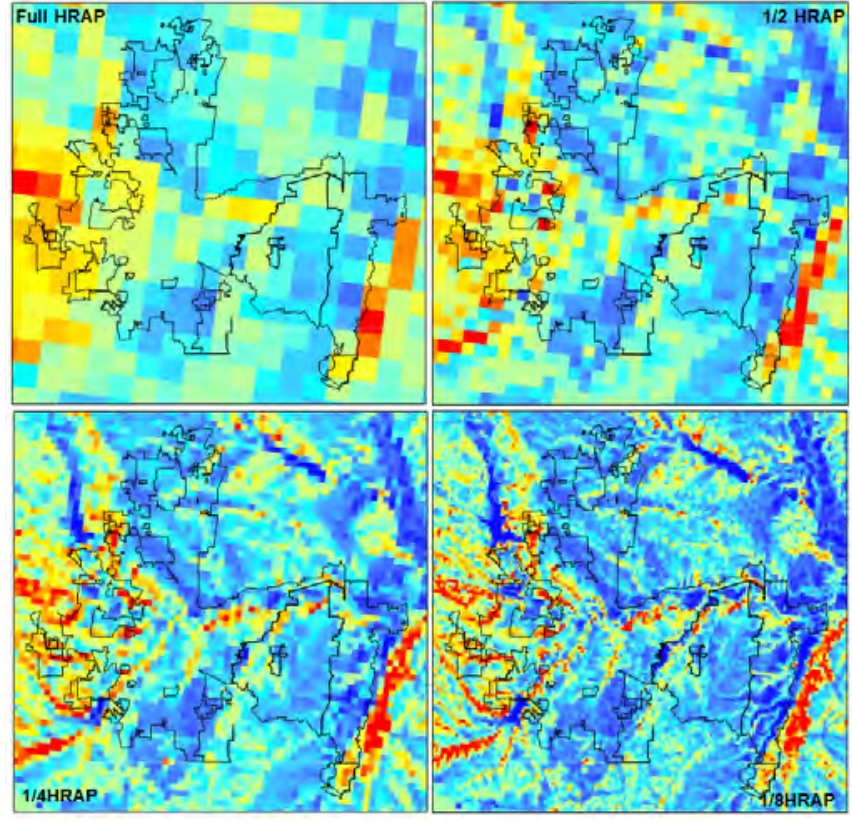

Figure 5 Maps of specific discharge at different spatial resolutions over the model domain: $4 \mathrm{~km}$ (upper left), $2 \mathrm{~km}$ (upper right), $1 \mathrm{~km}$ (lower left) and $500 \mathrm{~m}$ (lower right).
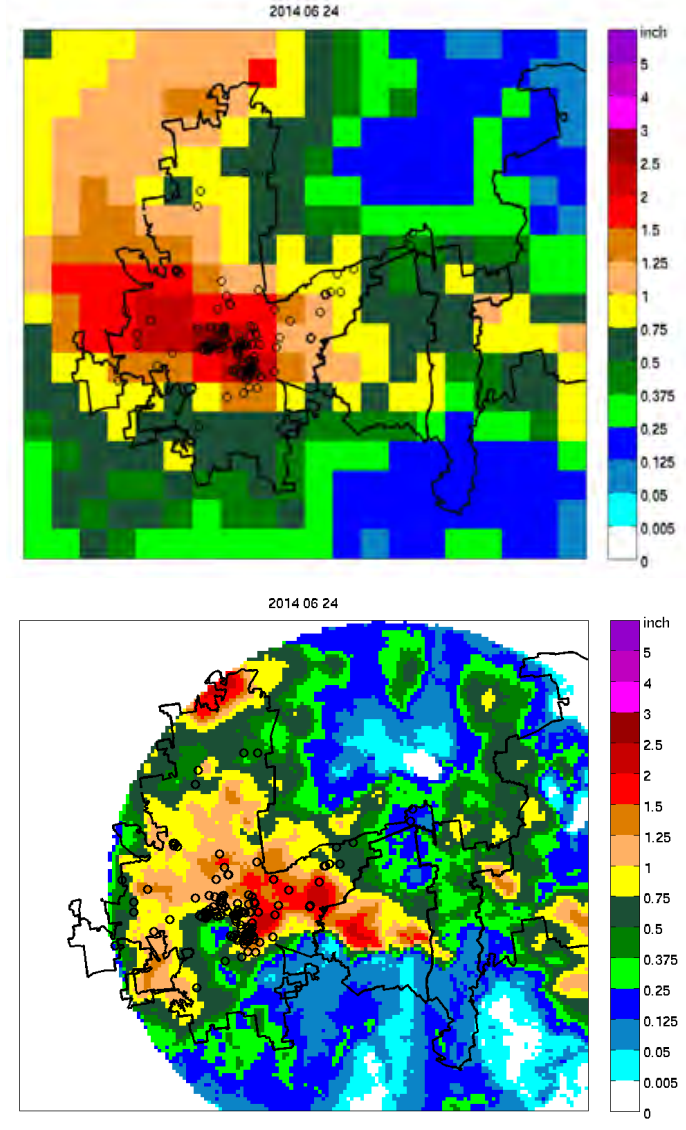

Figure 6 Total precipitation for 2014-06-24: (upper panel) MPE (1 HRAP, $1 \mathrm{~h}$ ) and (lower panel) CASA QPE (1/8 HRAP, $1 \mathrm{~min}) ; \mathrm{mm}=25.4 \times$ in. 
To warm up the model states, $\mathrm{HL}-\mathrm{RDHM}$ was run at a spatiotemporal resolution of 1 HRAP and $1 \mathrm{~h}$ using the MPE data from 1996 to 2014. The model was then run at spatiotemporal resolution of 1/8 HRAP ( 500 $\mathrm{m}$ ) and $1 \mathrm{~min}$ for 2014-06-24, using CASA QPE and MPE over the domain. For qualitative assessment of the model results, the flooding reports received by the City of Fort Worth from the residents throughout the event are used. Figure 6 shows the total precipitation for 2014-06-24, as observed by MPE (upper panel) and CASA QPE (lower panel).

As readily seen in Figure 6 above, the higher resolution CASA QPE presents details much better than the lower resolution MPE. There are, however, areas in the CASA QPE where rainfall amounts appear depressed due to attenuation. Note that for this study the CASA QPE was based only on the radar at the University of Texas at Arlington (XUTA) located at the center of the radar um-brella in the lower panel of Figure 6 . It is also noted that the CASA QPE products will soon be based on multiple radars, thereby greatly mitigating the ill effects of attenuation.

Figure 7 (opposite) and Figure 8 (below) show the hourly precipitation, hourly runoff and streamflow ending or valid at 16:00 on 2014-06-24, for the MPE and CASA QPE based results respectively. Note that in Figure 8 that CASA QPE is used within the XUTA umbrella but MPE is used elsewhere.

In Figures 7 and 8, the circles denote the locations of flooding as reported by the residents. The red circles indicate that flooding was first reported within the hour ending at 16:00. Figure 7 shows that most of the reports are located in the areas of heavy precipitation, and that the runoff and streamflow maps successfully narrow down the areas where most reports originated. The CASA QPE-forced results in Figure 8, on the other hand, show the ill effects of attenuation due to the fact that the QPE is derived only from a single X-band radar. As noted above, the effects of attenuation are expected to be addressed with network based QPE.

Comparison of the simulation results in Figures 7 and 8 indicates that higher resolution QPE and modeling improves location and temporal specificity of flooding threats, and that high-quality QPE is necessary to benefit from high resolution modeling.

For the above products to be readily utilized by the users it is necessary to translate them into easy-to-understand and actionable information.

Toward that end, the Threshold Frequency (TF) component of HL-RDHM (HL-RDHM 2009) will be added to the prototype system; it will express the streamflow map in terms of return periods, with which most engineers are familiar. Also, a decision support component based on indicator cokriging (Brown and Seo 2013; Seo et al. 2010; Seo 1996) is currently under development to de-lineate areas that are most likely to flood, the results of which will be reported in the near future.
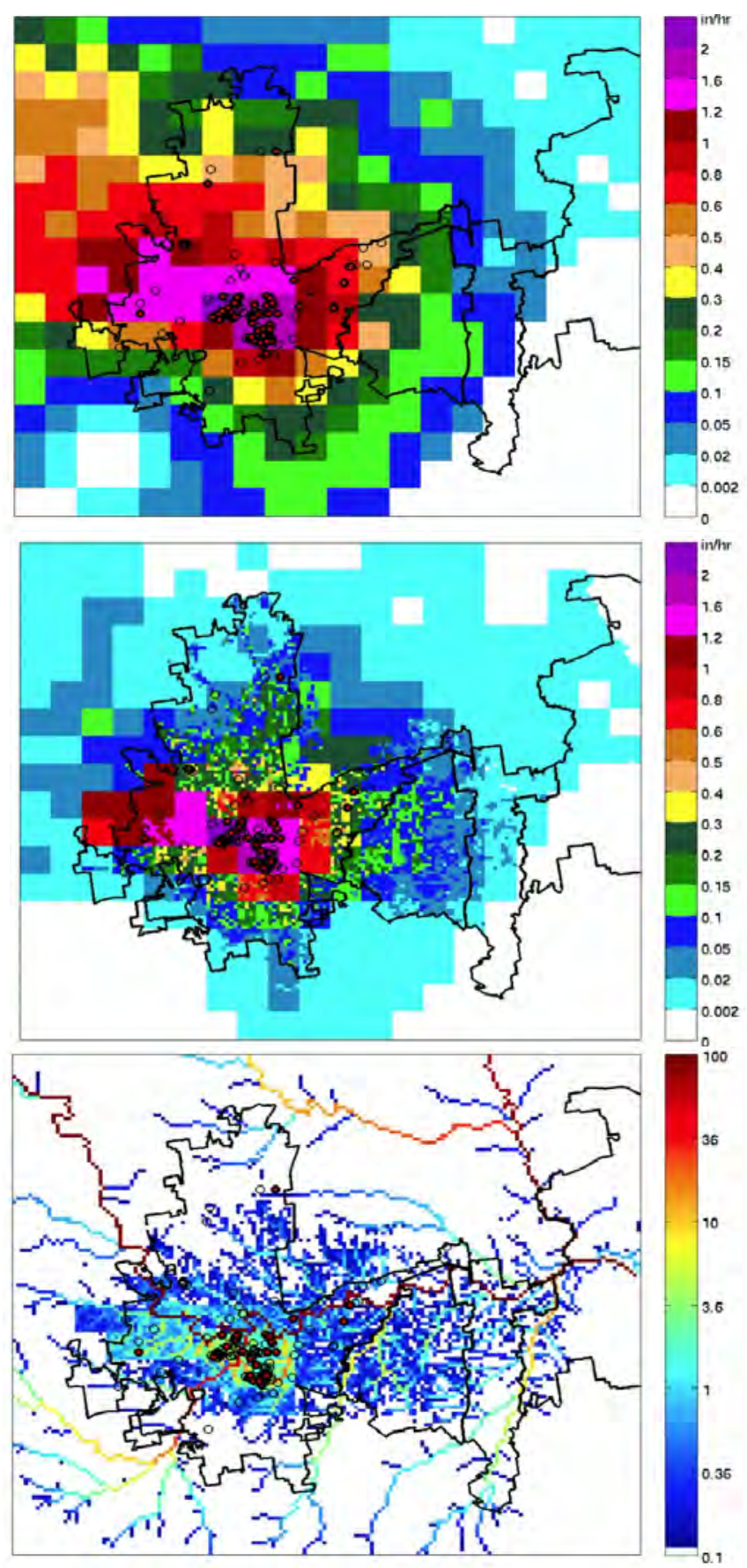

Figure 7 Hourly MPE precipitation (upper panel), hourly MPE-forced runoff (middle panel) and MPE-forced streamflow in CMS (lower panel), valid at 2014-06-24 $16: 00 ; \mathrm{mm}=25.4 \times$ in. 

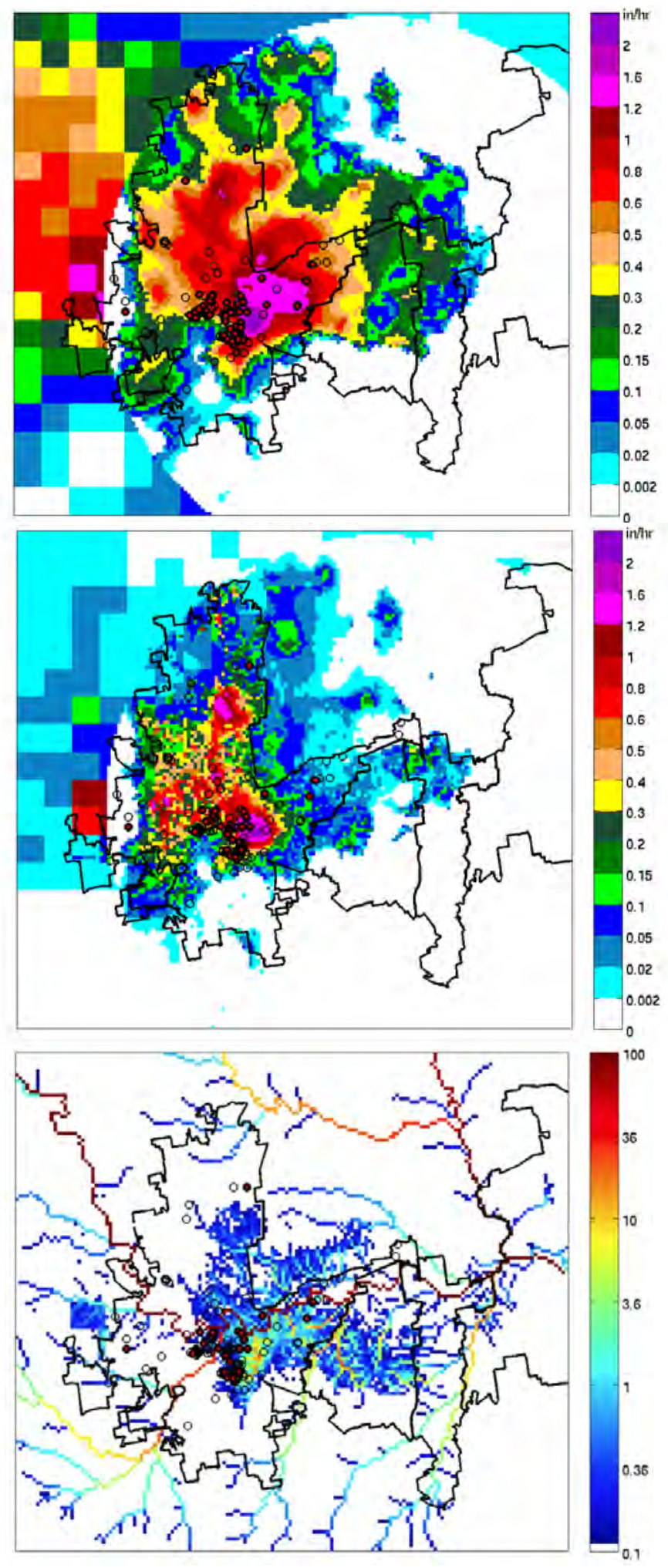

Figure 8 Hourly CASA precipitation (upper panel), hourly CASA QPE-based runoff (middle panel), and CASA QPE-based streamflow in CMS (lower panel) valid at 2014-06-24 16:00; $\mathrm{mm}=25.4 \times$ in.

\section{Conclusions}

The purpose of this paper is to describe the prototype high resolution flash flood forecast system under development for the areas of Fort Worth, Arlington and Grand Prairie in northern Texas and to qualitatively assess its performance through a case study of the flash flooding event of 2014-06-24 in Fort Worth. The hydrologic model used is HL-RDHM developed by the U.S. National Weather Service operating at a $500 \mathrm{~m}$ resolution. The precipitation input used are the radar QPE at $500 \mathrm{~m}$ and $1 \mathrm{~min}$ resolution from the DFW Demonstration Network of CASA radars and the MPE product operationally produced by the West Gulf River Forecast Centre with a spatiotemporal resolution of $4 \mathrm{~km}$ and $1 \mathrm{~h}$. The model simulation results are qualitatively assessed using the flooding reports received from the residents of Fort Worth throughout the event. The results indicate that higher resolution QPE and modeling improves location and temporal specificity of flooding threats, that high quality QPE is necessary to benefit from high resolution modeling, and that translation of the base products into easy-to-understand and actionable information is necessary for decision support of the users. It is expected that the benefits from high resolution distributed modeling are larger in large urban areas such that population density is high and increasing urbanization changes physiography. In such areas, the impact of climate change may be larger due to changing hydrologic and hydraulic conditions. The prototype flash flood prediction system is currently implemented for the spring storm season of 2015. Deployment of additional sensors and data collection are also under way and quantitative evaluation based on larger sample and network-based QPE will be reported in the near future.

\section{Acknowledgments}

This material is based upon work supported by the National Science Foundation, under IIP grant 1237767 (Brenda Philips, University of Massachusetts Amherst, principal investigator) and CCF grant 1442735 (principal investigators: Dong-Jun Seo, Michael Zink, Xinbao Yu, Zheng Fang, Jean Gao, UTA), and by the City of Fort Worth. These supports are gratefully acknowledged. The authors would like to thank Victor Koren (retired), Mike Smith, Zhengtao Cui and Brian Cosgrove of NWS/OHD for expert help on HLRDHM; Tom Donaldson (retired), Bob Corby (retired), Paul McKee, Greg Waller and Greg Story of NWS/WGRFC for providing various data and support; Tom Bradshaw and Greg Patrick of NWS/WFO Dallas-Fort Worth for helpful discussions and support; Seann Reed of NWS/MARFC for expert help on HLRDHM and derivation of routing parameters; Dave Streubel of NWS/APRFC for sharing experience with high resolution implementation of $\mathrm{HL}$ RDHM; Laura Pham of the City of Fort Worth for providing various GIS data; and Brenda Philips of the University of Massachusetts Amherst for providing the flood reports. 


\section{References}

Anderson, R. M., V. Koren and S. M. Reed. 2006. “Using SSURGO Data to Improve Sacramento Model A Priori Parameter Estimates." Journal of Hydrology 320 (1): 103-16.

Berne, A. and W. F. Krajewski. 2013. "Radar for Hydrology: Unfulfilled Promise or Unrecognized Potential?" Advances in Water Resources 51:357-66.

Bringi, V. N. and V. Chandrasekar. 2001. Polarimetric Doppler Weather Radar: Principles and Applications. Cambridge: Cambridge University Press.

Brown, J. D. and D.-J. Seo. 2013. “Evaluation of a Nonparametric Post-Processor for Bias Correction and Uncertainty Estimation of Hydrologic Predictions." Hydrological Processes 27 (1): 83-105. doi:10.1002/hyp.9263.

Burnash, R. J. C., R. L. Ferral and R. A. McGuire. 1973. A Generalized Streamflow Simulation System: Conceptual Modeling for Digital Computers. US Department of Commerce National Weather Service and State of California Department of Water Resources.

Chandrasekar, V. and R. Cifelli. 2012. “Concept and Principles of Rainfall Estimation from Radar: Multi Sensor Environment and Data Fusion." Indian Journal of Radio \& Space Physics 41:389-402.

Chandrasekar, V. and S. Lim. 2008. "Retrieval of Reflectivity in a Networked Radar Environment." Journal of Atmospheric and Oceanic Technology 25:1755-67.

Chow, V. T., D. R. Maidment and L. W. Mays. 1988. Applied Hydrology. New York: McGraw-Hill.

Dallas News. 2014. (http://thescoopblog.dallasnews. com/2014/06/page/4/).

David, C. H., D. R. Maidment, G.-Y. Niu, Z.-L. Yang, F. Habets and V. Eijkhout. 2011."River Network Routing on the NHDPlus Dataset." Journal of Hydrometeorology 12:913-34.

Fox4 news. 2014. (http://www.fox4news.com/flash-story/ 25860827/flooding-across-tarrant-county-on-tuesday)

HL-RDHM. 2009. Hydrology Laboratory-Research Distributed Hydrologic Model (HL-RDHM) User Manual v. 3.0.0 (Last Modified 12/29/09). http://www.cbrfc.noaa.gov/present/rdhm/RDHM_3_0_0_ User_Manual.pdf).

Jobson, H. E. 1996. Prediction of Traveltime and Longitudinal Dispersion in Rivers and Streams. Reston, VA: U.S. Geological Survey. Water Resources Investigations Report 96-4013. http://pubs.usgs.gov/wri/1996/4013/documents/dispersion.pdf.

Junyent, F., V. Chandrasekar, D. McLaughlin, D. Insanic and N. Bharadwaj. 2010. "The CASA Integrated Project 1 Networked Radar System." Journal of Atmospheric and Oceanic Technology 27:61-78. doi:10.1175/2009JTECHA1296.1.
Kitzmiller, D., S. V. Cooten, F. Ding, K. Howard, C. Langston, J. Zhang, H. Moser, Y. Zhang, J. J. Gourley, D. Kim and D. Riley. 2011. “Evolving Multisensor Precipitation Estimation Methods: Their Impacts on Flow Prediction Using a Distributed Hydrologic Model." Journal of Hydrometeorology 12: (6) 1414-31.

Koren, V. I., S. M. Reed, M. B. Smith, Z. Zhang and D.-J. Seo. 2004. "Hydrologic Laboratory Modeling System (HL-RMS) of the US National Weather Service." Journal of Hydrology 291:297318.

Koren, V. I., M. B. Smith and Q. Duan. 2003. Use of A Priori Parameter Estimates in the Derivation of Spatially Consistent Parameter Sets of Rainfall-Runoff Models. Chap 18 in Calibration of Watershed Models edited by Q. Duan, S. Sorooshian, H. Gupta, H. Rosseau and R. Turcotte, 239-54. Washington, DC:American Geophysical Union. doi:10.1002/9781118665671.ch18.

Koren, V. I., M. Smith, D. Wang and Z. Zhang. 2000. “Use of Soil Property Data in the Derivation of Conceptual RainfallRunoff Model Parameters." Presented at the15th Conference on Hydrology, American Meteorological Society, January 9-14, 2000, Long Beach, CA, 103-106. http://www.nws.noaa.gov/oh/hrl/papers/ams/ ams_2000_2.16.pdf.

Lim, S., V. Chandrasekar, P. Lee and A. P. Jayasumana. 2011. “Real-Time Implementation of a Network-Based Attenuation Correction in the CASA IP1 Testbed." Journal of Atmospheric and Oceanic Technology 28:197-209. doi:10.1175/2010JTECHA1441.1

McLaughlin, D. J., V. Chandrasekar, K. Droegemeier, S. Frasier, K. Kurose, F. Junyent, B. Philips, S. Cruz-Pol and J. Colom. 2005. “Distributed Collaborative Adaptive Sensing (DCAS) for Improved Detection, Understanding, and Prediction of Atmospheric Hazards." Presented at Ninth Symposium on Integrated Observing and Assimilation Systems for the Atmosphere, Oceans, and Land Surface (IOAS-AOLS), American Meteorological Society. Boston, MA: American Meteorological Society.

Rafieei Nasab, A., A. Norouzi, T. Mathew, D.-J. Seo, H. Chen, V. Chandrasekar, P. Rees and B. Nelson. 2014. "Comparative Evaluation of Multiple Radar-Based QPEs for North Texas." Presented at the 9th International Symposium on Weather Radar and Hydrology, April 7-10, 2000 organized by the Environmental and Water Resources Institute of the American Society of Civil Engineers.

Rafieei Nasab, A., A. Norouzi and D.-J. Seo and B. Nelson. 2015. "Improving High Resolution Quantitative Precipitation Estimation via Fusion of Multiple Radar-Based Precipitation Products." Journal of Hydrology 531 (2): 320-36. doi:10.1016/j.jhydrol.2015.04.066.

Reed, S., V. Koren, Z. Zhang, M. Smith and D.-J. Seo. 2002. “Distributed Modeling for Improved NWS River Forecasts." In Hydrologic Modeling for the 21st Century. Proceedings of the 
Second Federal Interagency Hydrologic Modeling Conference, July 28-August 1, 2002, Las Vegas, Nevada. http://acwi.gov/hydrology/mtsconfwkshops/conf_proceedings/second_fihmc_nevada.pdf.

Seo, D.-J. 1996. “Nonlinear Estimation of Spatial Distribution of Rainfall: An Indicator Cokriging Approach." Stochastic Hydrology and Hydraulics 10:127-50. doi:10.1007/BF01581763

Seo, D.-J., A. Seed and G. Delrieu. 2010. “Radar-Based Rainfall Estimation." In Rainfall: State of the Science, edited by F. Testik and M. Gebremichael, Geophysical Monograph 191, 79-104. Washington, DC: American Geophysical Union. doi:10.1029/2010GM000952.
Slack, J. R. and J. M. Landwehr. 1992. Hydro-Climatic Data Network: A U. S. Geological Survey Streamflow Data Set for the United States for the Study of Climate Variations, 1874-1988. Reston, VA: U.S. Geological Survey. Open-File Report 92-129. http://pubs.usgs.gov/of/1992/0129/report.pdf.

Zhang, Z., V. Koren, S. Reed, M. B. Smith and F. Moreda. 2006. "Comparison of Simulation Results Using SSURGO-Based and STATSGO-Based Parameters in a Distributed Hydrologic Model." In Proceedings of the Third Federal Interagency Hydrologic Modeling Conference April 2-6, 2006, Reno, Nevada.

http://acwi.gov/hydrology/mtsconfwkshops/conf_proceedings/3rdFIHMC/8D_ZhangZi.pdf. 